\title{
HISTOMORPHOLOGICAL FEATURES OF ATHEROSCLEROSIS IN THE LEFT ANTERIOR DESCENDING CORONARY ARTERIES AMONG BLACK KENYANS
}

\author{
Julius Ogeng'o, Beryl S. Ominde, Kevin W. Ongeti, Beda Olabu, Philip Maseghe, Judith Machira, Acleus \\ Murunga
}

Correspondence to Prof. Julius Ogeng'o, Department of Human Anatomy, University of Nairobi, E- Mail: jogengo@uonbi.ac.ke

\begin{abstract}
The pattern of coronary artery atherosclerosis is valuable in informing mitigation strategies for coronary heart disease. Histomorphological data on this disease among Africans living in Sub Saharan Africa are, however, scarce. The left anterior descending is one of the most commonly afflicted arteries. This study, therefore, examined the left anterior descending artery of 213 black Kenyans [Mean age 36.8 years, range 5- 82 years] who had died of non cardiovascular causes for features of atherosclerosis. The individuals were divided into male and female, then into 10-yr age groups. Specimens were obtained from the proximal segment of the artery during autopsy at the Department of Human Anatomy University of Nairobi, Kenya. They were processed routinely for paraffin embedding and sectioning. Five micron sections were stained with Haematoxylin/Eosin and Mason's trichrome and examined with light microscope. Micrographs of representative features were taken using a high resolution digital camera. At least one feature of atherosclerosis was present in $54(25.4 \%)$ of the individuals. The features observed included severe intimal hyperplasia $(34 ; 63 \%)$, disintegration of the internal elastic lamina [30; 55.6\%]; atherosclerotic plaque (20; 37\%), adventitial thicknening (14; $26 \%)$ and mural neovascularization $(10 ; 18.5 \%)$. The mean age of those with features of atherosclerosis was 38.4 years, range $6-62$ years with $25(46.3 \%)$ being aged 40 years and below. Of these, the male: female ratio was 1.7:1. In conclusion, features of atherosclerosis are present in over $25 \%$ of the population studied. The disease affects young people, including women. Proactive preventive measures including follow - up should commence early, and involve both men and women
\end{abstract}

\section{Keywords: Atherosclerosis, coronary, young, men, women, Kenya}

\section{INTRODUCTION}

Atherosclerosis of coronary arteries is one of the most common causes of ischemic heart disease (IHD) [Marzilli et al., 2012; Jha et al., 2013]. The incidence of IHD is rising in Sub Saharan Africa (SSA) consequent to epidemiological and demographic transitions (Mensah, 2008; Nkoke and Luchuo, 2015). Currently, the disease constitutes a substantial cause of morbidity and mortality in the region (Ikem and Sumpio, 2011; Essien et al., 2014; Ebireri et al., 2016). In Kenya, acute myocardial infarction is not uncommon (Ogeng'o et al., 2010a), is the most common cause of cardiovascular deaths (Ogeng'o et al., 2011) and may cause $10-20 \%$ of heart failure (Ogeng'o et al., 2014a; Bloomfield et al., 2016). There is fear of a looming epidemic of coronary heart disease (CHD) unless deliberate measures are taken to mitigate the imminent rise (Churchill, 2013; Ebireri, 2016). Reliable data are important to inform these measures. Histopathological studies on coronary artery 
disease (CAD) are an important source of data for improving understanding of the disease (Abedinzadeh et al., 2015) but are scarce from SSA. Among Kenyans, we recently demonstrated features of atherosclerosis in over $20 \%$ of carotid arteries (Ogeng'o et al., 2017) but studies on coronary arteries are scarce. The left anterior descending (LAD) artery is one of the most commonly afflicted arteries (Golshahi et al., 2005; Vyas et al., 2015). This study therefore investigated the distribution of histomorphological features of atherosclerosis in proximal LAD among black Kenyans.

\section{MATERIALS AND METHODS}

This study was done on autopsy material from samples of 213 victims of trauma at the Department of Human Anatomy, University of Nairobi for whom the next of kin were able to provide adequate medical history. It included only individuals whose next of kin reported no record of cardiovascular disease or history of the conventional risk factors namely hypertension, diabetes mellitus, cigarette smoking, atherogenic diet, overt psychosocial stress, HIV infection or antiretroviral therapy. Ethical approval was provided by the Kenyatta National Hospital / University of Nairobi Ethics and Research Committee. Informed consent was provided by the next of kin who brought the body to the Chiromo Funeral Parlour. Permission was granted by the Chairman of Department. The cases were obtained by systematic sampling in which every $4^{\text {th }}$ case from individuals who had died of trauma were examined. The age range was $6-82$ years. The subjects were divided into male and female and then into 10 year age groups as follows: $0-10,11-$ $20,21-30,31-40,41-50,51-60,61-$ $70,71-80$ and over 80 years. The pericardium was removed, the left coronary artery (LCA) and its LAD branch identified. Cases of variant branching of LCA were excluded from the study, to eliminate the concomitant anatomical predisposition to atherosclerosis.

Two (2) $\mathrm{mm}$ long specimens were taken from the proximal LAD within 72 hours of death, to avoid overt postmortem damage to the tissues. They were fixed by immersion in $10 \%$ formaldehyde solution for three days, then trimmed and routinely processed for paraffin embedding by passing them through increasing concentrations of isopropyl alcohol, and cleared with cedar wood oil for 12 hours. The sections were then infiltrated with fresh molten paraplast wax for 12 hours. Seven micrometer sections were stained with Haematoxylin/Eosin and Mason's trichrome for demonstration of the general organization of the mural components. The slides were then examined at various magnifications for conventional features of atherosclerosis namely intimal hyperplasia, degeneration of the tunica media, atherosclerotic plaques, adventitial thickening and neovascularization. Micrographs of representative features were taken using a high resolution digital camera (Sony - DSC - HX400 20.4 - Megapixel (C) attached to a photomicroscope.

\section{RESULTS}

Of the 213 cases, there were 135 males and 78 females, distributed in 9 ten - year age groups. Mean age was 36.8 years (range $5-$ 82 years). One hundred and thirty nine of them $(65.2 \%)$ were aged below 50 years with $23(10.8 \%)$ being under 20 years. Twelve $(5.6 \%)$ of them were in the first decade. One hundred and sixty three (76.5\%) were aged $21-50$ and 115 (54\%) were between $21-40$ years (Fig 1 ). 


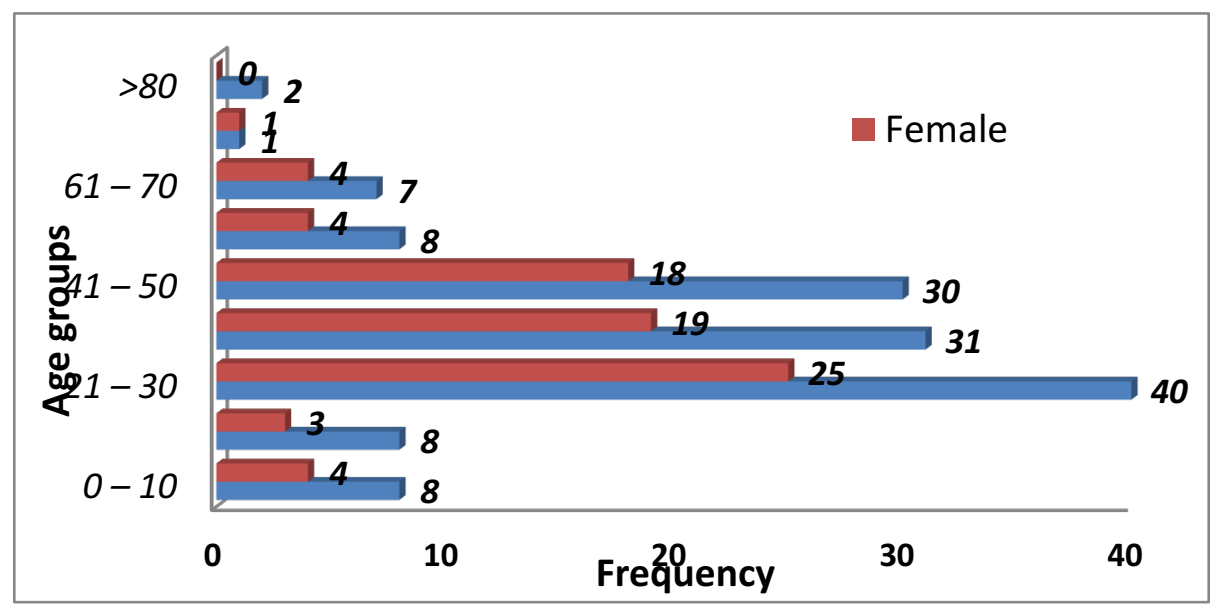

Figure 1: Age Distribution of the population whose LAD was studied

\section{General Observations}

The LAD was a muscular artery with the conventional three tunics namely tunica intima, media and adventitia (Fig 2a,b). At least one feature of atherosclerosis was present in $54(25.4 \%)$ of all cases. In total, 6 main features of atherosclerosis were observed, namely severe intimal hyperplasia, atherosclerotic plaque, disintegration of IEL, medial degeneration, adventitial thickening and mural neovascularization (Table 1). In $34(63 \%)$, cases there was severe intimal hyperplasia (Fig 2c). In 17 (50\%) of these cases, the tunica intima alone was greater than the tunica media and adventitia combined (Figure 2d) and in 11 (32.4\%) of the cases it was so severe that it occluded the lumen (Figure 2e). In 20 (37\%) cases, parts of the intima had degenerated due to atherosclerotic plaque formation (Figure 2f). The tunica adventitia was remarkably thickened in the absence of intimal hyperplasia in $14(25.9 \%)$ cases [Fig 2a]. Neovascularization of the tunica adventitia was evident (Fig $2 \mathrm{c}$ ) in 10 (18.5\%) of cases (Table 1).

Table 1: Distribution of features of atherosclerosis

\begin{tabular}{|l|lllr|l|}
\hline Feature & \multicolumn{3}{|l|}{ Frequency } & (\%) \\
\hline Severe Intimal Hyperplasia & M & F & Total & \\
\hline Disintegration of IEL & 22 & 12 & 34 & 63 \\
\hline Atherosclerotic Plaque & 18 & 12 & 30 & 55.6 \\
\hline Medial degeneration & 12 & 8 & 20 & 37 \\
\hline Adventitial thickening alone & 10 & 10 & 20 & 37 \\
\hline Mural neovascularization & 8 & 6 & 14 & 25.9 \\
\hline & 5 & 4 & 10 & 18.5 \\
\hline
\end{tabular}




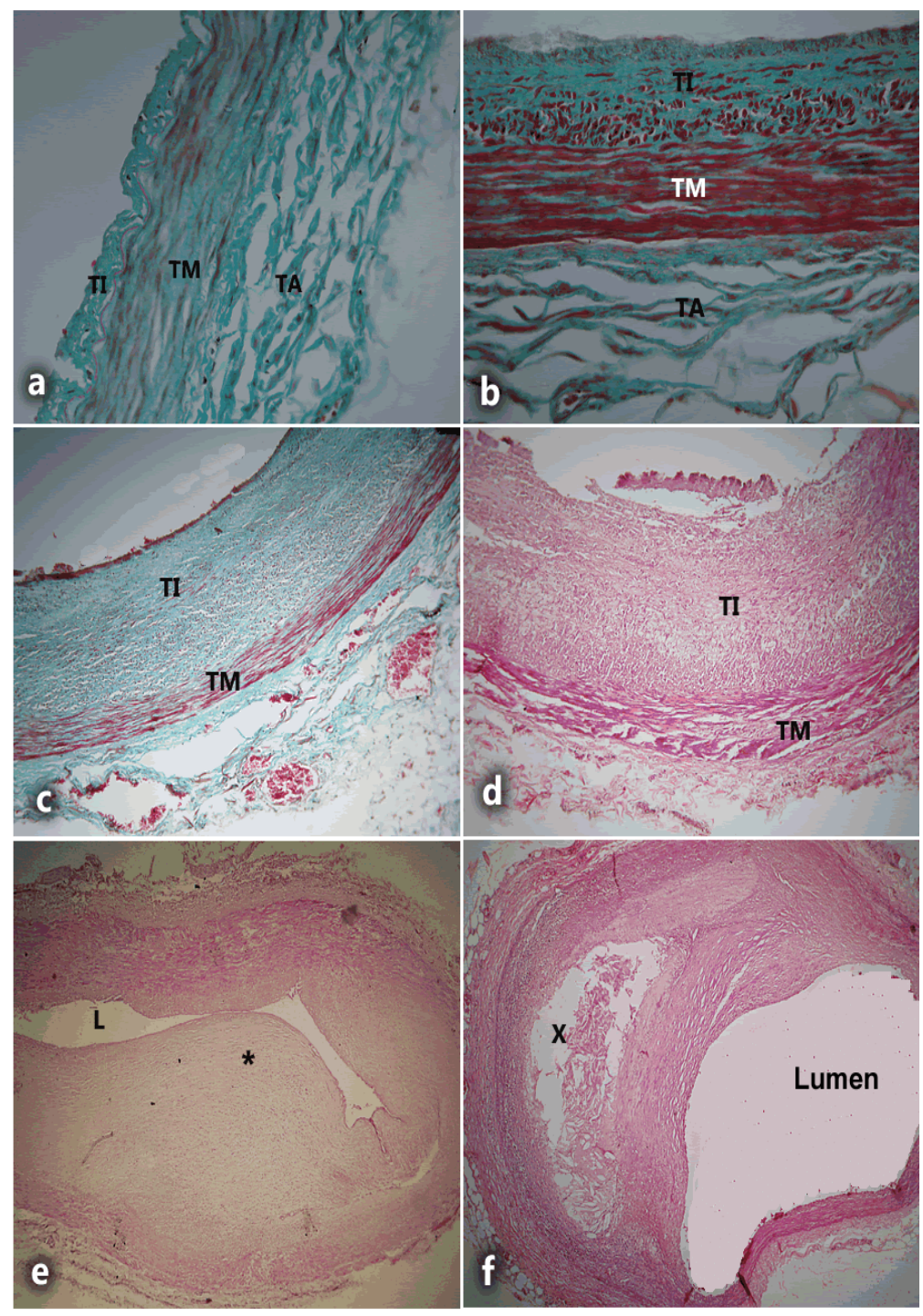

Fig 2 a - $f$ : Degrees of intimal hyperplasia in proximal LAD of black Kenyans. TI = Tunica intima; TM = Tunica media; TA = Tunica adventitia. Mason's trichome and Hematoxylin/Eosin x100. A. Full wall thickness in LAD of 25 year old male showing the usual three tunics. B - Slight intimal hyperplasia in a 31 year old female. Note the tunica intima (TI) is about the same size as the tunica media (TM). C - Moderate to severe hyperplasia in a 36 year old male. Note the tunica intima (TI) is double the size of the tunica media (TM). D - Severe intimal hyperplasia in a 38 year old male. The tunica intima (TI) is more than double the tunica media (TM). E - Very severe intimal hyperplasia (star) in a 9 year old male. Note partial occlusion of the lumen, leaving only a slit lumen (L). F - Atherosclerotic plaque ( $\mathrm{x}$ ) in a 39 year old male.

The hypertrophied tunica intima was highly cellular. The cells were mainly observed in the deeper layer of intimal thickening and were of various shapes and sizes (Figure $2 b$ - d; Fig 3a). They also took different

\section{Degeneration of internal elastic lamina}

The internal elastic lamina was often disintegrated at multiple sites to leave gaps. orientations. One of the major limitations of this study was that the cells were not characterized. However, the different shapes of the nuclei suggest that they were of different varieties.

In some of the gaps, cells could be seen traversing between the tunica media and intima (Figure $3 b$ ). In cases of moderate to 
severe intimal hyperplasia, the IEL was altogether not discernible and the tunica intima appeared to merge with the tunica media imperceptibly (Fig $2 \mathrm{c}-\mathrm{e}$ ).

\section{Degeneration of tunica media}

The tunica media was, in many the cases, markedly attenuated (Figure 3c). As the tunica intima increased, the tunica media diminished in size. There were gaps between SMC, and spaces between the layers of smooth muscle, suggestive of degeneration
(Fig 3c, d). Incase of atherosclerotic plaque, the tunica media was not discernible.

\section{Adventitial thickening}

There was distinct thickening of the tunica adventitia in $14(25.9 \%)$ of the cases. In several of them, the tunica adventitia was thickened with only slight intimal thickening (Figure 3d). In a few cases, the adventitial thickening preceded intimal thickening (Figure 2a; and 3d).
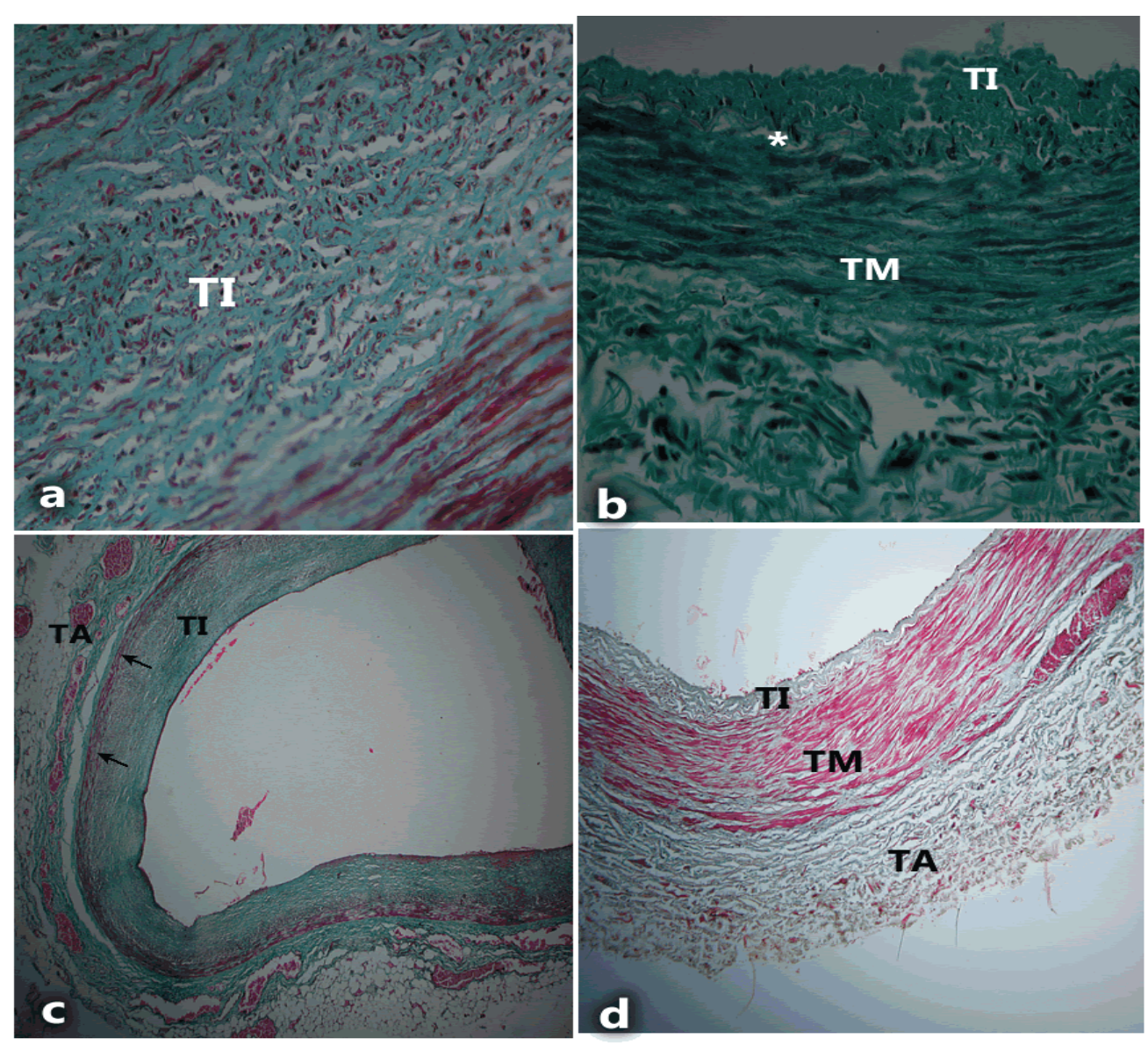

Figure $3 \mathrm{a}-\mathrm{d}$ : Histomorphological features of atherosclerosis in LAD of black Kenyans. TI = Tunica intima; TM = Tunica media; TA = Tunica adventitia. Mason's trichrome and Hematoxylin/Eosin. A - Hyper cellularity of intimal thickening in a 36 year old male. Note the abundance of cells of various sizes and shapes in TI x400. B Disintegration of IEL, causing gaps (star) in a 62 year old female. $x 400 . C$ - Attenuation of tunica media in a 43 year old male. Note the very markedly thinned out smooth muscle layer (arrows) $x 40 . D$ - Thickening of the tunica adventitia (TA) making almost the same size as the tunica media (TM) in a 35 year old male. $x 100$. 


\section{Mural neovascularization}

The other distinct feature was mural neovascularization. In $10(18.5 \%)$ cases there was profuse proliferation of the vasa vasora in the tunica adventitia (Figure 4a). The vasa vasora invaded the tunica media, with the vessels running between the layers of smooth muscle in 3 cases (Figure $4 b$ ). In 2 cases of very severe intimal hyperplasia, vessels were noted in the tunica intima (Figure 4c).

\section{Age and gender distribution}
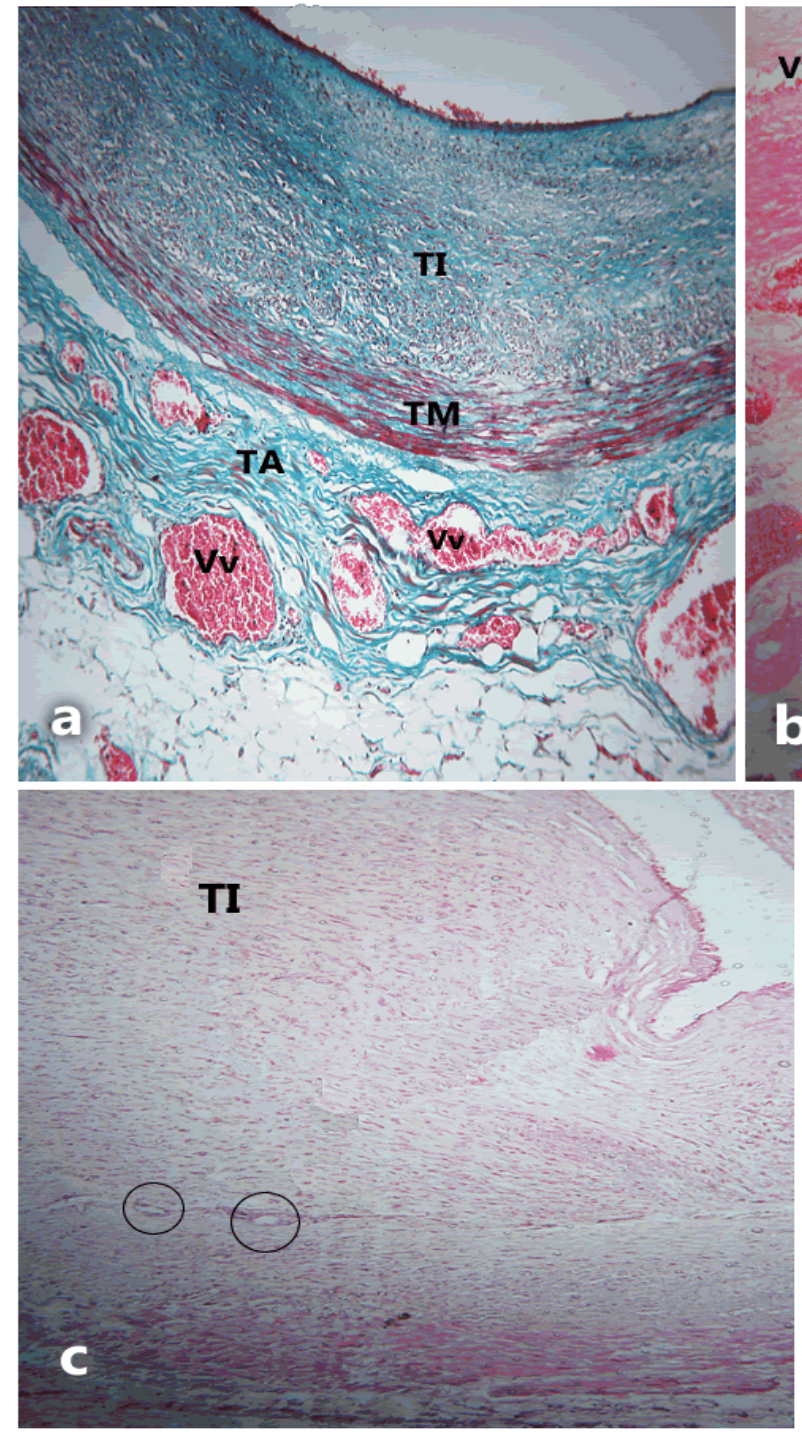

The mean age of those with features of atherosclerosis was 38.4 years (Range 6 62 years). Majority were aged below 50 years, with $25(46.3 \%)$ being below 40 years. Two $(3.7 \%)$ were aged below 10 years and $4(7.4 \%)$ were teenagers. Only $15(27.8 \%)$ were over 50 years old (Fig 6). There was a male predominance in all age groups with overall male: female ratio of 1.7:1. Male predominance was most pronounced between $31-60$ years (Figure 5).

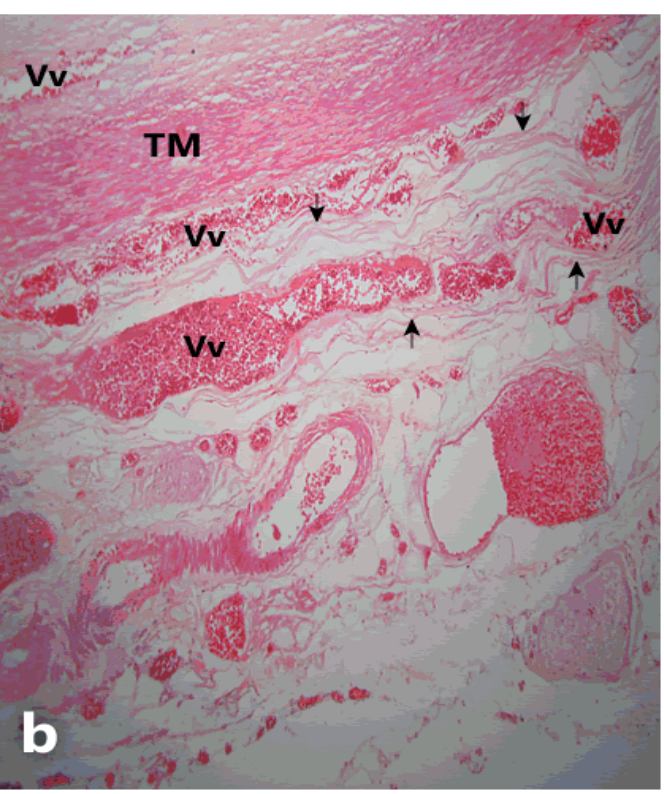

Figure 4 a - c: Neovascularization in the wall of LAD of black Kenyans. TI = Tunica intima; TM = Tunica media; TA $=$ Tunica adventitia. A - Profuse proliferation of the vasa vasora ( $v v)$ in the tunica adventitia (TA) of a 51 year old male. Mason's trichrome stain x 100. B Vasa vasora (vv) in the outer layer of the tunica media of a 41 year old female. Note the vasa vasora appearing to split the smooth muscle cell layer (arrows). Haematoxylin / Eosin stain x 400. C - Vasa vasora (circled) in markedly thickened tunica intima of a 42 year old male. Haematoxylin / Eosin stain $\times 400$ 


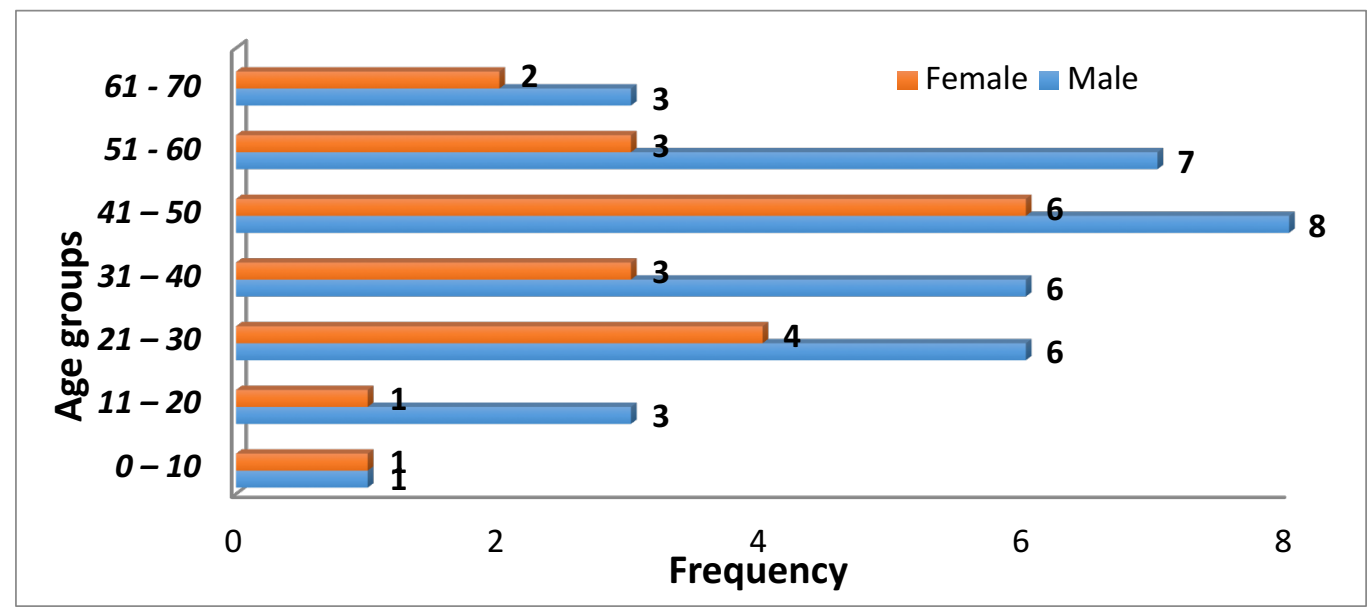

Figure 5: Age and gender distribution of cases with features of atherosclerosis

\section{DISCUSSION}

In the present study, features observed in the arterial wall which are consistent with various stages of atherosclerosis include intimal hyperplasia (Cizek et al., 2007; Subbotin, 2016); intimal hypercellularity (Libby et al., 2011; Bobryshev et al., 2011; Orekhov et al., 2014); disruption of elastic fibres in the internal elastic lamina (Koniari et al., 2011); degeneration of tunica media (Clarke et al., 2008; Bennett et al., 2016); adventitial thickening (Falk et al., 2009; Skilton et al., 2009; Stenmark et al., 2013; Wang et al., 2013) and mural neovascularization (Fleiner et al., 2004; Moreno et al., 2006; Hildebrandt et al., 2008). These observations revealed that all layers of the arterial wall are involved in atherosclerosis and confirmed our recent report that features of atherosclerosis do occur in the tunica adventitia (Ogeng'o et al., 2014b). This extensive involvement suggests that the disease is already established in the arteries and supports our earlier submission that atherosclerotic disease is a real problem which should no longer be considered uncommon among Kenyans (Ogeng'o et al., 2010a).

These features of atherosclerosis were found in $25.4 \%$ of the study population. This is much higher than $2 \%$ reported in the same population over 15 years ago (Saidi et al., 2002), comparable to $21 \%$ reported in Ethiopia (Maru, 1989) and $28.9 \%$ in Iran (Golshali et al., 2005) but lower than those reported from several Indo - Asian and Caucasian countries (Table 2).

This comparatively high prevalence is consistent with recent reports that myocardial infarction has become more common in the Kenyan population than it was 15 - 20 years ago (Ogeng'o et al., 2010a; 2014a; Bloomfield et al., 2016). In 20 (9.4\%) of the total study population, there were atherosclerotic plaques. This is consistent with the prevalence of 2 $11 \%$ reported for various populations (Al Nozha et al., 2014). The variability revealed in Table 2 suggests geographical variations probably dependent on the profile of risk factors. The apparent increase in the Kenyan population may be attributed to the demographic and epidemiological transitions occurring in Kenya (Fengler, 2009; Gatongi et al., 2015). This implies that the disease may continue to rise unless deliberate control measures are instituted to contain it. 
Table 2: Prevalence of coronary atherosclerosis in selected countries

\begin{tabular}{|l|l|l|}
\hline Reference & Country & \multicolumn{1}{|c|}{$\begin{array}{c}\text { Percent Prevalence of coronary } \\
\text { atherosclerosis }\end{array}$} \\
\hline Al - Nozha et al., 2004 & Saudi Arabia & 5.5 \\
\hline Golshahi et al., 2005 & Iran & 28.9 \\
\hline Kim et al., 2013 & Korea & 48.5 \\
\hline Maru, 1989 & Ethiopia & 21 \\
\hline Saidi et al., 2002 & Kenya & 2 \\
\hline Tabib and Loire, 1993 & France & 34 \\
\hline Tuzcu et al., 2001 & America & 51.9 \\
\hline Vyas et al., 2015 & India & 73.5 \\
\hline Westerman et al., 2015 & Germany & 16.5 \\
\hline Current Study & Kenya & 25.4 \\
\hline
\end{tabular}

The most remarkable finding of the present study, however, was that in $2(3.7 \%)$ cases (1 male; 1 female) the features were present the first decade and in $4(7.4 \%)$ cases ( 3 males; 1 female) they were present in the second decade. This indicated that in $6(11.1 \%)$ of the cases, the features were present in individuals aged 20 years and below. Features of atherosclerosis in the first decade have not been reported before. This precocious commencement is concordant with reports that exposure to risk factors may trigger atherosclerosis from an early age including in the prenatal stage (Matturi et al., 2003; Skilton, 2008; Frantz et al., 2012). Indeed, our earlier report indicated histomorphometric evidence of early onset of coronary heart disease (Ogeng'o et al., 2010b). The features observed usually correlate with risk factors (Cizek et al., 2007; Skilton et al., 2011, 2012). Their presence in the first decade is consistent with presence of risk factors in women of reproductive age in the Kenyan population (Mathenge et al., 2010; Joshi et al., 2014; Muchira et al., 2015) which would imply potential for prenatal exposure to these factors. Presence of features of atherosclerosis in the second decade, is on the other hand, consistent with many literature reports (Mc Gill et al., 2000; Cheng, 2001; Skilton et al., 2008; Modelli et al., 2011; Vyas et al., 2011). These findings imply that, like in other populations, control of atherosclerosis should commence early in life, including during the pre natal period.

In $46.3 \%$ of cases, the features were present in those aged 40 years and below, the so called young CAD. The high prevalence appears at variance with most studies which report 5 $10 \%$ prevalence among South Asians and 1 $2 \%$ in other ethnic groups (Aggarwal et al., 2016). Recent angiographic studies among Iraqis, however, revealed prevalence of $31 \%$ (Mohammad et al., 2015). The prevalence of $46.3 \%$, however, appears concordant with intracoronary ultrasound studies which revealed over $50 \%$ prevalence of young CAD among asymptomatic young adults and children (Tuzcu et al., 2001). This suggests that the prevalence of young CAD shows geographical and perhaps ethnic differences, but fundamentally, it may be higher than currently perceived for most populations. These observations reveal wide diversity perhaps related to profile of risk factors and age distribution of the population. Pertinent to this suggestion are the findings that the implicated risk factors namely family history, male gender, hypertension, obesity, smoking, alcohol intake, diabetes mellitus (Yang et al., 2014; Albarqy et al., 2015; Aggarwal et al., 2016) are also rampant in the population (Mathenge et al., 2010; Ayah et al., 2013; Joshi et al., 2014; Muchira et al., 2015). Early onset coronary atherosclerosis is consistent with our recent report that over $30 \%$ victims of 
myocardial infarction are aged 50 years and younger (Ogeng'o et al., 2010b). Control measures should therefore target these risk factors, commence in the prenatal period and be deployed continuously.

The male predominance in the current study is also consistent with previous reports that myocardial infarction is more common in males (Ogeng'o et al., 2010a; 2011), supporting the suggestion that male gender is a major nonmodifiable risk factor (Albarqy et al., 2015). Among women, it is generally believed that endogeneous premenopausal estrogen protects them from coronary artery disease (Subbiah, 1993; Meyer et al., 2014; Romano et al., 2016). A remarkable finding of the current study, at variance with this assertion, is that there are substantial numbers of females affected in all age groups. This supports recent reports that $\mathrm{CHD}$ is a problem even in premenopausal women and should not be underestimated (Maas and Appelman, 2010). This unexpected presence in women may be related to the prevalence of risk factors for atherosclerosis among Kenyan women (Joshi et al., 2014; Muchira et al., 2015). These findings suggest that preventive measures should also target young women.

In conclusion, features of coronary artery atherosclerosis are present in over $25 \%$ of the population studied. They are present in all layers of the arterial wall and represent various stages of disease development. The disease starts in the first decade, affects young people, increases with age and though affecting more males, a significant proportion of young women are afflicted. This suggests that subclinical atherosclerosis is an established problem in the black Kenyan population. Proactive preventive measures including follow - up should commence early, and involve both men and women to mitigate the effects.

ACKNOWLEDGEMENTS: We are grateful to Jacob Gimongo and Margaret Irungu for their technical assistance, and Antonina Odock - Opiko for typing the manuscript.

CONFLICT OF INTEREST: There is no conflict of interest in this study

\section{REFERENCES}

1. Abedinzadeh N, Pedram B, Sadeghian Y, Nodushan SM, Gilasgar M, Darvish et al. 2015. A histopathological analysis of the epidemiology of coronary atherosclerosis: an autopsy study. Diagnostic Pathol, 10: 87. doi:10.1186/s $13000-015-0324-y$.

2. Aggarwal A, Srivastava S, Velmurugan M. 2016. Newer perspectives of coronary artery disease in young. World J Cardiol, 8: 728 - 734.

3. Al - Nozha MM, Arafah MR, Al - Mazrou YY, Al - Maatouq MA, Khan NB, Khalil MZ et al. 2004. Coronary artery disease in Saudi Arabia. Saudi Med J, 25: 1165 - 1171.

4. Albarqy G, Balgith M, Almallah M. 2015. What are the predictors of coronary artery disease in young Saudi Arabian patients. J Cardiol Curr Res, 4: 00135.DOI.10.15406/jccr.2015. 04.00135.

5. Bennet MR, Sinha S, Owens GK. 2016. Vascular smooth muscle cells in atherosclerosis. Circ Res, 118: $692-702$.

6. Bloomfield GS, De Long AK, Akwanalo CO, Hogan JW, Carter EJ, Aswa DF et al. 2016. Markers of atherosclerosis, clinical characteristics and treatment patterns among middle aged patients with heart failure in Kenya. Glob Heart, 11: $97-107$.

7. Bobryshev YV, Karagodin VP, Kavalevskaiia ZI, Miasoedova VA, Shapyrina EV, Saliamov VI et al. 2011. Number of cells and cell proliferation in intima of different human arteries. Tsitologiia, 53: 815 - 825.

8. Churchill LO. 2013. Epidemiology of ischemic heart disease in Sub Saharan Africa. Cardiovasc J Afr, 24: $34-42$.

9. Cizek SM, Bedri S, Talusan P, Silva N, Lee H, Stone JR. 2007. Risk factors for atherosclerosis and the development of preatherosclerotic intimal hyperplasia. Cardiovasc Pathol, 16: $344-350$. 
10. Clarke MCH, Littlewood TD, Figg N, Maguire JJ, Davenport AP, Goddard M, et al. 2008. Chronic Apoptosis of vascular smooth muscle cells Accelerates Atherosclerosis and promotes calcification and medial degeneration. Circulation Research, 102: 1529 - 1538.

11. Ebireri J, Aderemi AV, Omoregbe N. 2016. Interventions addressing risk factors of ischemic heart disease in Sub Saharan Africa: A systematic Review. BMJ Open; 6:e011881.

12. Essien OK, Andy J, Ansa V, Asuquo A, Udoh A. 2014. Coronary artery disease and the profile of cardiovascular risk factors in South Nigeria: A clinical and autopsy study. Cardiology Res Pract, http://dx.doi.org/10.1155/2014/804751.

13. Falk E, Thim T, Kristensen IB. 2009. Atherosclerotic plaque, adventitia, perivascular fat, and carotid imaging. JACC: Cardiovascular Imaging, 2009; 2: 183 - 186.

14. Fengler W. 2009. Demographic transition and growth in Kenya: World bank computations based on United Nations. World population prospects.

15. Fleiner M, Kummer M, Mirlacher M, Saliter G, Cathomas G, Krapf R, et al. 2004. Arterial neovascularization and inflammation in vulnerable patients: early and late signs of symptomatic atherosclerosis. Circulation, 110:2843-2850.

16. Frantz E, Menezes HS, Lange KC, Abegg MP, Correa CA, Zangali L et al. 2012. The effect of maternal hypercholesterolemia on placenta and fetal arteries in rabbits. Acta Bras Chir, 27: 7 - 12.

17. Garg M, Aggarwal AD, Kataria SP. 2011. Coronary atherosclerosis and myocardial infarction. An autopsy study. J Ind Acad Forensic Med, 33; $39-42$.

18. Gatongi PM, Songa J, Kiyiapi L. 2015. The principles of epidemiological transitions and the experiences in Kenya. Pinnacle Med Sci, 2: $689-692$.

19. Golshahi J, Rajabi P, Golshahi F. 2005. Frequency of atherosclerotic lesions in coronary arteries of autopsy specimens in Isfahan Forensic Medicine Centre. J Res Med Sci, 1: 16 - 19.

20. Hildebrandt HA, GossI M, Mannheim D, Herrmann J, Spendlove D, Bajanowski T, et al. 2008. Differential distribution of vasa vasorum in different vascular beds in Human. Atherosclerosis, 199: $47-54$.

21. Iken I, Sumpo BE. Cardiovascular disease: the new epidemic in Sub Saharan Africa. SAGE Journals, 2011; 19

22. Jha B, Naik D, Agarwal A, Jana S, Patel M. 2013. Incidence of atherosclerosis in different coronary arteries and its relation with myocardial infarction. A randomized study in 300 autopsy hearts in a tertiary care hospital. Int J Med Scie and Public Health, 2: $836-839$.

23. Joshi MD, Ayah R, Njau EK, Wanjiru R, Kayima JK, Njeru EK. 2014. Prevalence of hypertension and associated cardiovascular risk factors in Urban slum in Nairobi, Kenya: A population based survey. BMC Public Health, 14: 1177.

24. Kim M-S, Kang S - J, Lee C - W, Han S, Park D - W, Lee S - W et al. 2013. Prevalence of coronary atherosclerosis in asymptomatic Healthy Study of Donor Hearts. J Atheroscler Thromb, 20: $465-471$.

25. Koniari I, Marrilas D, Papadaki H, Karanikolas M, Mandellou M, Papalois A et al. 2011. Structural and biomechanical alterations in rabbit thoracic aortas as associated with progression of atherosclerosis. Lip Health Dis, 10: 125. http:dx.doiorg/10.1186/1476 - 511X - $10-125$.

26. Libby P, Ridker PM, Hanson GK. 2011. Progress and challenges in translating the biology of atherosclerosis. Nature, 473: $317-325$.

27. Maas AHEM, Appelman YEA. 2010. Gender differences in coronary heart disease. Neth Heart J, 18: 596 602.

28. Madelli MES, Cherulli AS, Gandolfi L, Pratesi R. 2011. Atherosclerosis in young Brazillians suffering violent deaths: a pathological study. BMC Research Notes; 4: 531. Doi : 10.1186//1756-0500-4 531.

29. Maru M. 1989. Coronary atherosclerosis and myocardial infarction in autopsied patients in Gondar Ethiopia. J R Soc Med, 82: 399 - 401.

30. Marzalli M, Merz NB, Boden WE, Bonow RO, Capozza PG, Chillian WM et al. 2012. Obstructive coronary atherosclerosis and ischemic heart disease: An elusive link. J Am Coll Cardiol, 11: 951 - 956.

31. Mathenge W, Forster A, Kuper H. 2010. Urbanization, ethnicity and cardiovascular risk in a population transition in Nakuru, Kenya: a population based survey. BMC Public Health, 10: 569. doi:10.1186/1471 $2458-10-569$. 
32. Matturi L, Lavezzi AM, Ottaviani G, Rossi L. 2003. Intimal preatherosclerotic thickening of the coronary arteries in human fetuses of smoker mothers. J Thromb Haem, 1: 2234- 2238.

33. Mc Gill Jr HC, Mc Mahan CA, Herderick EE, Malcom GT, Tracy RE, Strong JP et al. 2000. Origin of atherosclerosis in childhood and adolescents. Am J Clin Nutr, 70: 1307s - 1315s.

34. Mensah G. 2008. Ischaemic heart disease in Africa. Heart, 94:836-843.

35. Meyer MR, Fredette NC, Howard TA, Hu C, Ramesh C, Daniel C et al. 2014. G Protein - coupled estrogen receptor protector from atherosclerosis. Scientific Reports; 4: 7564. Doi : 10.1038.srep 07564.

36. Mohammad AM, Jehanger HI, Shaikhow SK. 2015. Prevalence and risk factors for premature coronary artery disease in patients undergoing coronary angiography in Kurdistan, Iraq. BMC Cardiovasc Disord, 15: 155. Doi:10.1186/s12872-015-0145-7.

37. Moreno PR, Purushothman R, Fuster V, O' Connor WN. 2002. Intimomedial interphase damage and adventitial inflammation is increased beneath disrupted atherosclerosis in the aorta. Circulation, 105: $2504-2511$.

38. Muchira J, Stuart - Shor E, Kariuki J, Mukuna A, Ndirigirigi I, Gabage L et al. 2015. Distribution and characteristics of risk factors for cardiovascular - metabolic diseases in a rural Kenyan community. Int J Afr Nursing Sci, 3: $76-81$.

39. Nkoke C, Luchuo EB. Coronary heart disease in Sub Saharan Africa: Still rare, misdiagnosed or underdiagnosed? Cardiovasc Diag Ther, 2015; doi10.3978/jissn.2223 - 3652.2015.05.01.

40. Ogeng'o JA, Olabu BO, Ong'era D, Sinkeet SR. 2010a. Pattern of acute myocardial infarction in an African Country. Acta Cardiol, 65: $613-618$.

41. Ogeng'o J, Kilonzi J, Saidi H, Hassanali J. 2010b. Histomorphometric evidence of early onset coronary arytery disease among Kenyans. MEDICOM Afr J Hosp Sci Med, 19 - 24: 11 - 14.

42. Ogeng'o JA, Gatonga P, Olabu BO. 2011. Cardiovascular causes of death in an East African Country: an autopsy study. Cardiol J, 18: $67-72$.

43. Ogeng'o J, Gatonga PM, Olabu BO, Ogeng'o MN. 2014a. Pattern of heart failure in an adult Kenyan population. Int J Cardiovasc Res, 3: 6. http://dx.doi.org/10.4172/2324 - 8602.1000185.

44. Ogeng'o J, Ongeti KW, Obimbo M, Olabu B, Mwachaka P. 2014b. Features of atherosclerosis in the tunica adventitia of coronary and carotid arteries in a black Kenyan population. Anat Res Int, Vol 2014, p $1-5$. http://dx.doi.org/10.1155/2014/456741.

45. Ogeng'o J, Ongeti K, Mwachaka P. 2017. Features of atherosclerosis of common carotid arteries among black Kenyans. J Morphol Sci, 34: 54 - 57.

46. Romano IJ, Lenatti L, Franco N, Misuraca L, Morici N, leuzzi C et al. 2016. Menopause atherosclerosis and cardiovascular risk: a puzzle with too few pieces. Ital J Gender - Specific Med, 2: $110-116$.

47. Saidi HS, Olumbe AK, Kalebi A. 2002. Anatomy and pathology of coronary arteries in adult black Kenyans. E Afr Med J, 79: 323-327.

48. Skilton MR. Intrauterine risk factors for precocious atherosclerosis. 2008. Pediatrics, 121: $570-574$.

49. Skilton MR, Serusclat A, Sethu AH, Brun S, Bernard S, Baikau B et al. 2009. Noninvasive measurement of carotid extra-media thickness: associations with cardiovascular risk factors and intima-media thickness. JACC Cardiovasc Imaging; 2:176-82.

50. Skilton MR, Boussel L, Bonnet F, Benard S, Douek PC, Moulin P. 2011. Carotid intima - media and adventitial thickening: comparison of new and established ultrasound and magnetic resonance imaging techniques. Atherosclerosis, 215: $405-410$.

51. Skilton MR, Sullivan TR, Ayer JG, Harmer JA, Toelle BG, Webb K et al. 2012. Carotid extra - medial thickness in Childhood: early life effects on the arterial adventitia. Atherosclerosis, 222: $478-482$.

52. Stenmark K, Yeager M, El Kasmi KC, Nozik - Grayck E, Gerasimovskaya EV, Li M. 2013. The adventitia: essential regulator of vascular structure and function. Ann Rev Pysiol, 75: 23 - 47.

53. Subbiah MT. 1998. Mechanisms of cardioprotection by estrogens. Proc Soc Exp Med, 217: 23 - 29.

54. Subbotin VM. 2016. Excessive intimal hyperplasia in human coronary arteries before intimal lipid depositions is the initiation of coronary atherosclerosis constitutes a therapeutic target. Drug Discovery Today, 21: $1578-1595$.

55. Tabib A, Loire R. 1993. Unexpected sudden death and coronary lesions. Apropos of 407 cases out of 1000 deaths in patients under 65 years of age. Arch Mal Coeur Vaiss, 86: $401-406$. 
56. Tuzcu EM, Kapadia SR, Tutar E, Ziada KM, Hobbs RE, et al. 2001. High prevalence of coronary atherosclerosis in asymptomatic teenagers and young adults: evidence from intravascular ultrasound. Circulation, 103: 2705 -2710.

57. Vyas P, Gonsai RN, Meenakshi C, Nanavati NG. 2015. Coronary atherosclerosis in non cardiac death: an autopsy study. J Midlife Health, 6: $5-9$.

58. Wang JL, Ma SQ, Li L, Liu GQ, Hu WC, Ma R. 2013. Correlation of inflammatory cells in adventitia and formation and extending of atherosclerotic lesions in coronary artery of apolipoprotein $\mathrm{E}$ Knockout mice. Chin J Physiol; 56: $77-82$.

59. Westerman D, Savvatis K, Wollenberg U, Limberg R, Maier LS, Bauersachs J. 2015. Prevalence of obstructive coronary disease in ambulatory patients with stable angina pectoris. J Exp Cardiol, 6: 387. Doi:10.4172/2188-9880.1000387.

60. Yang WX, Yang Z, Wu YJ, Qiao SB, Yang YJ, Chen JL. 2014. Factors associated with coronary artery disease in young population age <40 years: analysis with 217 cases. Chin Med Sci J, 29: $36-42$. 